\title{
A novel cement-based technology for the treatment of fluoride ions
}

\author{
Shivali V. Tarali ${ }^{1} \cdot$ Nayana P. Hoolikantimath ${ }^{1} \cdot$ Nagalakshmi Kulkarni $^{1} \cdot$ Praveen A. Ghorpade $^{1}[$
}

Received: 30 October 2019 / Accepted: 29 May 2020 / Published online: 13 June 2020

(c) Springer Nature Switzerland AG 2020

\begin{abstract}
Previous studies have confirmed the effective removal of fluoride by cured cement paste powder from wastewaters originating from semiconductor and fertilizer industries. However, the mineralogical changes taking place in cement paste during fluoride removal were not reported. There is need to understand the significance of cement hydration products and performance of different types of cements in fluoride removal. The present study shows the fluoride removal efficiency using different types of cement, such as cement containing calcium sulfate dihydrate, cement containing calcium sulfate anhydrate, clinker and Ordinary Portland Cement (OPC). OPC gave the best result with $61.1 \%$ of fluoride removal efficiency within $5 \mathrm{~h}$ of reaction time, and reduction the followed pseudo-first-order kinetics. Further, the column studies were carried out using granules of OPC run under two different conditions, by passing the solution containing only fluoride ions and another condition in which the mixture of fluoride and nitrate was passed to see the reduction efficiencies of OPC granules. The results showed a $91 \%$ reduction in fluoride ions on fourth day of cement hydration in former condition; however, the reduction was less when mixture was passed. Further, to understand the mineralogical and morphological changes in cement during anionic removal reactions, analytical tools such as X-ray diffraction (XRD) and scanning electron microscope (SEM) were used.
\end{abstract}

Keywords Fluoride · Solidification/stabilization · Cement types · Ettringite · lon-exchange · Batch experiments · Column experiments $\cdot$ Mineralogical studies

\section{Introduction}

Fluorine is the 13th most abundant halogen element distributed throughout the earth [1]. Fluorine is always present in the combined form as fluoride compounds. The sources of fluoride may occur from natural sources or by anthropogenic activities of humans [2]. Drinking water is considered to be safe and beneficial for human consumption if fluoride concentration does not exceed $1.5 \mathrm{mg} / \mathrm{L}$ $[3,4]$.The researches have reported that the fluoride concentrations in water beyond $1.5 \mathrm{mg} / \mathrm{L}$ have adverse effects on dental, skeletal, reproductive, developmental, renal, neurological, endocrine, gastrointestinal and have carcinogenic effects [2]. Fluorosis (skeletal and dental effects) occurs when fluoride ion interacts with the mineralizing tissues causing retardation in the mineralization process in the tissues. Endemic situations of fluorosis have been reported in more than 20 developed and developing nations [5]. Hence, to eliminate high fluoride concentration problem from polluted water, various conventional methods such as coagulation and precipitation, adsorption, membrane techniques and ion-exchange process are reported $[5,6]$. Several studies have been reported in

Electronic supplementary material The online version of this article (https://doi.org/10.1007/s42452-020-2986-7) contains supplementary material, which is available to authorized users.

Praveen A. Ghorpade, praveenghorpade1@gmail.com | ${ }^{1}$ Department of Civil Engineering, KLE Dr. M. S. Sheshgiri College of Engineering and Technology, Udyambag, Belagavi, Karnataka 590008, India. 
which clay, minerals are used in column studies to reduce fluoride concentration $[7,8]$.

In recent decades, cement-based solidification/stabilization $(s / s)$ is gaining importance for the treatment of polluted water [9]. Previous researchers have also proved that cement-based system also has the ion-exchange capacity [10]. Chemistry of cement, cement hydration products and their ion-exchange capacity for the pollutants on their surface, near-surface and interstitial sites make cement a potential candidate for the treatment of ground water pollutants [11]. During the hydration of cement, important mineral responsible for ion-exchange is ettringite $\left(\mathrm{Ca}_{6} \mathrm{Al}_{3} / \mathrm{Fe}_{3}\left(\mathrm{SO}_{4}\right)_{3}(\mathrm{OH})_{12} \cdot 26 \mathrm{H}_{2} \mathrm{O}\right.$ ) (AFt phase-Aluminate Ferrite tri-anion phase that has general constitutional formula $\left[\mathrm{Ca}_{3}(\mathrm{Al}, \mathrm{Fe})(\mathrm{OH})_{6} \cdot 12 \mathrm{H}_{2} \mathrm{O}_{2} \cdot \mathrm{X}_{3} \cdot x \mathrm{H}_{2} \mathrm{O}\right.$ where $x$ is normal, at least, $\leq 2$ and $X$ is one formula unit of a doubly charged, or with reservations, two formula units of a singly charged anion) [12]. Ettringite is formed mainly because of the reactions between aluminate/ferrite and different forms of calcium sulfate. Equations 1 and 2 represent the formation of ettringite $[12,13]$. During the ion-exchange process, the sulfate ion is replaced with the pollutant anion. Mainly anions like $\mathrm{OH}^{-}, \mathrm{CO}_{3}{ }^{2-}, \mathrm{NO}_{3}{ }^{-}, \mathrm{F}^{-}, \mathrm{AsO}_{4}{ }^{3-}, \mathrm{B}(\mathrm{OH})_{4}{ }^{-}$, $\mathrm{CrO}_{4}{ }^{2-}, \mathrm{MoO}_{4}{ }^{2-}, \mathrm{SeO}_{4}{ }^{2-}, \mathrm{SO}_{3}{ }^{2-}$ and $\mathrm{VO}_{4}{ }^{3-}$ may serve as substitute for sulfate in ettringite [13]. The presence of forms of calcium sulfate may change the formation rates of ettringite in the cement. Forms of calcium sulfate like dihydrate calcium sulfate $\left(\mathrm{CaSO}_{4} \cdot 2 \mathrm{H}_{2} \mathrm{O}\right)$ (natural gypsum), hemihydrate calcium sulfate $\left(\mathrm{CaSO}_{4} \cdot 0.5 \mathrm{H}_{2} \mathrm{O}\right)$ prepared by heating calcium sulfate dihydrate at $130^{\circ} \mathrm{C}$, anhydrate calcium sulfate $\left(\mathrm{CaSO}_{4} \cdot 0.001 \mathrm{H}_{2} \mathrm{O}\right)$ prepared by heating calcium sulfate dihydrate at (soluble) $170{ }^{\circ} \mathrm{C}$ and (insoluble) at $200^{\circ} \mathrm{C}$. Literatures have proved that cement containing anhydrate form of calcium sulfate (soluble) has given the best result for the formation of ettringite that assists in the removal of anionic pollutants [14].

$\mathrm{C}_{3} \mathrm{~A}+3 \mathrm{CaSO}_{4}+32 \mathrm{H}_{2} \mathrm{O} \rightarrow 3 \mathrm{CaO} \cdot \mathrm{Al}_{2} \mathrm{O}_{3} \cdot 3 \mathrm{CaSO}_{4} \cdot 32 \mathrm{H}_{2} \mathrm{O}$ two types of cement (namely cement containing dihydrate form of calcium sulfate and cement containing anhydrate form of calcium sulfate). Further, a comparative analysis was carried out utilizing the synthesized types of cements (dihydrate, anhydrate), clinker and OPC through series of batch experiments to examine the removal mechanism of fluoride from synthetically prepared fluoride solution. Finally, Ordinary Portland Cement (OPC) was used as reactive media in the column experiments, and fluoride reduction efficiency was investigated. Column studies were carried out for two conditions namely, removal of only fluoride ion as well as simultaneous removal of fluoride and nitrate ion. XRD and SEM were carried out to study the mineralogy and morphology of the solids generated during the removal of fluoride ion.

\section{Materials and methods}

\subsection{Materials}

The chemicals used were fluoride (NaF, Nice Chemicals $\mathrm{LR}$ grade $97 \%$ assay), potassium nitrate $\left(\mathrm{KNO}_{3}\right.$, Nice Chemicals LR grade $99 \%$ assay), white phenol $\left(\mathrm{C}_{6} \mathrm{H}_{5} \mathrm{OH}\right.$, Jyothi Chemicals LR grade, $99 \%$ assay), potassium hydroxide ( $\mathrm{KOH}$, Nice Chemicals LR grade, $85 \%$ assay), zirconium oxychloride $\left(\mathrm{ZrOCl}_{2} \cdot 8 \mathrm{H}_{2} \mathrm{O}\right.$, Nice Chemicals LR grade $99 \%$ assay), SPADNS AR (2-(p-Sulphophenylazo) 1,8- dihydroxynaphthalene-3,6- disulphonic acid trisodium salt, Loba Chemicals LR grade), barium chloride $\left(\mathrm{BaCl}_{2}\right.$, Nice Chemicals LR grade $99 \%$ assay), clinker powder (Bagalkot Cements India Ltd), the chemical composition of which is given in Table $\mathrm{S} 1$ [18], calcium sulfate $\left(\mathrm{CaSO}_{4} \cdot 2 \mathrm{H}_{2} \mathrm{O}\right.$, Nice chemicals LR grade, $98.5 \%$ assay) and Ordinary Portland Cement (OPC, Zuari high strength cement, 43 grade), the chemical composition of which is given in Table S2 [19]. Stock fluoride and potassium nitrate in $1000 \mathrm{~mL}$ of milli-Q demineralized water, respectively.

$6 \mathrm{Ca}^{+2}+2 \mathrm{Al}, \mathrm{Fe}(\mathrm{OH})_{4}^{-}+3 \mathrm{SO}_{4}^{2-}+4 \mathrm{OH}^{-}+26 \mathrm{H}_{2} \mathrm{O} \rightarrow \mathrm{Ca}_{6}\left[(\mathrm{Al}, \mathrm{Fe})(\mathrm{OH})_{6}\right]_{2}\left(\mathrm{SO}_{4}\right)_{3} \cdot 26 \mathrm{H}_{2} \mathrm{O}$

Types of cement have been previously used for the removal of organic contaminants like trichloroethylene (TCE) [14] and other anionic pollutants like nitrates, arsenic and phosphates $[15,16]$. Cured cement paste powder has been utilized for the treatment of high fluoride concentration coming from fertilizer industries and semiconductor fabrications [17]. However, the utilization of types of cement and their mineralogical behavior have not been explored for the reduction in fluoride in drinking water. Therefore, the present study deals with the synthesis of

\subsection{Methods}

Fluoride, nitrate, sulfate and calcium analysis of samples were carried out by procedures given in standard methods [20]. Concentrations of fluoride, nitrate and sulfate were analyzed at wavelengths $570 \mathrm{~nm}, 410 \mathrm{~nm}$ and $420 \mathrm{~nm}$, respectively, using UV-Digital spectrophotometer. Digital pH meter (Systronics, MK VI) was used to analyze $\mathrm{pH}$; Conductivity was analyzed using Conductivity-TDS Meter 308 (Systronics). At the end of the fluoride reduction 
experiments, XRD analysis was carried out for the dried cement sample using X-ray diffractometer (Rigaku smart lab) with $2 \theta$ values ranging from $5^{\circ}$ to $90^{\circ}$ at a scanning speed of $1 \% \mathrm{~min}$. To study the surface morphology, SEM (JOEL JSM-6360) analysis was carried out for the cement samples. The entire experimentation and the treatment were carried out at ambient room temperature.

\subsection{Synthesis of cement}

Two different types of cement were synthesized by mixing clinker (passing through $75 \mu \mathrm{m}$ sieve) and two different forms of calcium sulfate separately.

As per the results of TGA (Thermo Gravimetric Analysis) analysis from the previous literature obtained, two forms of calcium sulfate namely calcium sulfate dihydrate $\left(\mathrm{CaSO}_{4} \cdot 2 \mathrm{H}_{2} \mathrm{O}\right)$ and calcium sulfate anhydrate (insoluble heated at $\left.200{ }^{\circ} \mathrm{C}\right)\left(\mathrm{CaSO}_{4} \cdot 0.001 \mathrm{H}_{2} \mathrm{O}\right)$ were used in the present study [14]. The dosage of dihydrate form of calcium sulfate and anhydrate (insoluble) form of calcium sulfate was kept at $5 \%$ and was added to clinker separately in two glass bottles. The bottles were then tumbled at $40 \mathrm{rpm}$ for uniform mixing of clinker and forms of calcium sulfate (dihydrate and anhydrate) to obtain cement. Two types of cements were synthesized in which water was not added in the process; however, different types of gypsum which had different chemically bound moisture were used to synthesize different types of cement. It is chemically bound moisture associated with gypsum. Thus, synthesized cement was used in batch and column experiments in the study.

\subsection{Batch experiments}

The experiments were performed in clean acid-washed Pyrex glass vials of $30 \mathrm{~mL}$ capacity. The synthetic fluoride solution with initial fluoride concentration of $30 \mathrm{mg} / \mathrm{L}$ was prepared. The fluoride solution was allowed to react with different types cements used in the study with cement to fluoride solution $(\mathrm{S} / \mathrm{L})$ ratio maintained at $1: 10$, i.e., $1 \mathrm{~g}$ of cement and $10 \mathrm{~mL}$ of fluoride solution of $30 \mathrm{mg} / \mathrm{L}$. All the experiments were performed with respective duplicate control samples (only $10 \mathrm{~mL}$ of fluoride solution of $30 \mathrm{mg} / \mathrm{L}$ ) and triplicate experimental samples. To avoid settling of cement and to ensure proper mixing, the vials were kept on end to end rotation at $40 \mathrm{rpm}$ using the rotor for varying contact time. The vials were retrieved at the appropriate time; the batch studies were carried out for varying time intervals from 0 th $\mathrm{h}$ to 5 th $\mathrm{h}$. The samples were analyzed at every 1-h interval. The samples were subjected to centrifuge at $1000 \mathrm{rpm}$ for $5 \mathrm{~min}$ to separate fluoride solution and cement. The supernatant was then filtered through Whatman filter paper 40, and the filtered solution was taken for fluoride analysis. The cement after reactions was oven-dried, stored in a desiccator, and acetone was passed to stop the further hydration reactions. The experiments were performed with above-mentioned procedure for four types of cement, cement containing $5 \%$ dihydrate form of calcium sulfate, cement containing 5\% anhydrate form of calcium sulfate, clinker and OPC.

The $\mathrm{pH}$ and conductivity were also regularly monitored for all sets of experiments. The dried cement samples were taken for X-ray diffraction (XRD) and scanning electron microscope (SEM) analysis. XRD analysis was performed for the best results obtained.

\subsection{Column experiments}

Column experiments were carried out to investigate the fluoride removal efficiency of cement. The column was constructed with acrylic material with $(6 \times 6 \times 66) \mathrm{cm}$ dimensions $(\mathrm{W} \times \mathrm{B} \times \mathrm{L})$. The column was filled with cement granules of varying sizes from 5 to $12 \mathrm{~mm}$. The granules were made using water to cement $(\mathrm{W} / \mathrm{C})$ ratio of 0.3 . Granules were prepared by mixing $1000 \mathrm{~g}$ of OPC with $300 \mathrm{~mL}$ of water. The bed height of cement granules was maintained at $35 \mathrm{~cm}$. Batch experiments had a contact time of fluoride solution and cement up to $5 \mathrm{~h}$ in these experiments cement powder was used, which gave better reduction efficiency. However, in column experiments, cement granules were used with lesser contact time of fluoride solution. $30 \mathrm{mg} / \mathrm{L}$ of fluoride solution did not give considerable reduction, so the fluoride concentrations were brought down to $10 \mathrm{mg} / \mathrm{L}$. The initial inlet fluoride concentration for column experiment was kept at $10 \mathrm{mg} / \mathrm{L}$. An overhead tank with capacity of $15 \mathrm{~L}$ was provided. Fluoride solution was allowed to flow under gravity with controlled flow rate. The flow rate was optimized to $40 \mathrm{~mL} / \mathrm{min}$. Similarly, for checking the simultaneous removal of fluoride and nitrate, the initial inlet mixed fluoride and nitrate synthetic solution of $10 \mathrm{mg} / \mathrm{L}$ concentration were prepared and rest of the parameters like cement bed height, water: cement ratio and flow rate were maintained uniform, and the $\mathrm{pH}$ was measured throughout the experiment. The XRD and SEM analysis were carried out for best obtained result. Figure S1 represents the column set up with cement granules as filler material.

\section{Results and discussions}

\subsection{Fluoride removal efficiency of different types of cements}

Series of batch experiments were performed to determine the removal of fluoride using four types of cement, cement 
containing $5 \% \mathrm{CaSO}_{4} \cdot 2 \mathrm{H}_{2} \mathrm{O}, 5 \%$ insoluble $\mathrm{CaSO}_{4} \cdot 0.001 \mathrm{H}_{2} \mathrm{O}$, clinker (without gypsum) and OPC (commercially available 43 grade). The behavior of fluoride removal was monitored in $5 \mathrm{~h}$ equilibrium experiments at constant $S / L$ ratio $(1: 10)$. Initial concentration of synthetic fluoride stock solution was maintained at $30 \mathrm{mg} / \mathrm{L}$. Figure 1 shows the effect of cement containing $5 \% \mathrm{CaSO}_{4} \cdot 2 \mathrm{H}_{2} \mathrm{O}$, cement containing $5 \%$ insoluble $\mathrm{CaSO}_{4} \cdot 0.001 \mathrm{H}_{2} \mathrm{O}$, clinker and $\mathrm{OPC}$ on the reduction in fluoride concentration at different time interval (0th $\mathrm{h}-5$ th $\mathrm{h}$ ). At the end of $5 \mathrm{~h}$ reaction time, the fluoride ion reduction was highest for commercial OPC with $61.1 \%$ efficiency and the least reduction efficiency was observed with cement containing $5 \%$ insoluble $\mathrm{CaSO}_{4} \cdot 0.001 \mathrm{H}_{2} \mathrm{O}$ with $33.3 \%$. The clinker, the cement containing $5 \%$ $\mathrm{CaSO}_{4} \cdot 2 \mathrm{H}_{2} \mathrm{O}$ showed reduction efficiencies of $52.8 \%$ and $50 \%$, respectively.

According to previous studies, cement containing calcium sulfate anhydrate (soluble) showed [14] the highest reactivity in the reduction in pollutant. However, the present study contradicts the findings. This is perhaps due to less dissociation of anhydrous form of insoluble $\mathrm{CaSO}_{4} \cdot 0.001 \mathrm{H}_{2} \mathrm{O}$ in the cement during the course of reaction. As insoluble anhydrate form of calcium sulfate is less reactive, minerals such as ettringite are likely to form in less quantity. In such cases, freely available calcium oxide in cement could play role in fluoride reduction. Cement containing calcium sulfate dihydrate always showed less reactivity, as the dissociation of calcium sulfate dihydrate is slow. The clinker experiment clearly showed that fluoride reduction could be achieved without the addition of any form of calcium sulfate. The calcium compounds such as $C_{3} S, C_{2} S, C_{3} A$ and $C_{4} A F$ could play an important role in fluoride reduction. OPC experiments gave the best results of all the above batch experiments.

One of the possible reasons for better reduction efficiency of commercial OPC could be, during the manufacturing of OPC the calcium sulfate in dihydrate form (3-5\%)

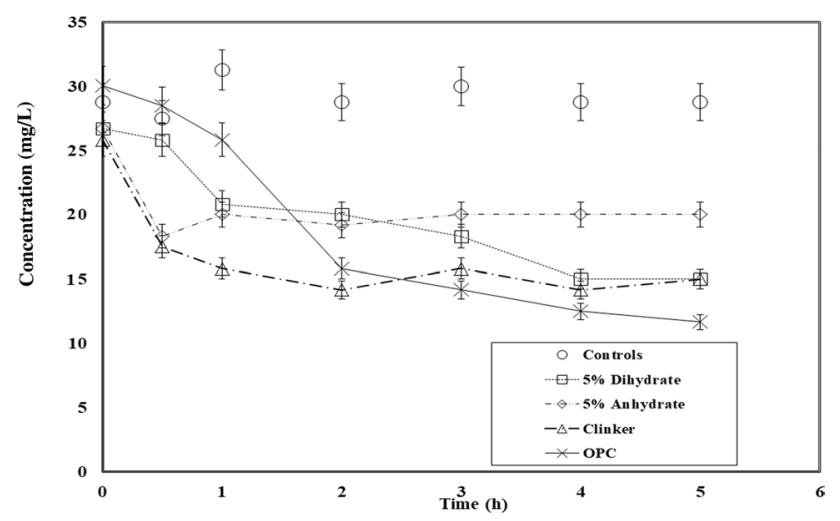

Fig. 1 Concentrations of fluoride at different time intervals with different types of cement slurry and controls is added at the time of grinding in milling operation. Due to the heat generated in the ball mill operation the calcium sulfate dihydrate changes its form partly into hemihydrate and soluble anhydrate. These forms of calcium sulfates have a significant effect on hydration products generated, like formation of ettringite. For this reason, the temperature in milling process of OPC is controlled so as to optimize the different forms of calcium sulfate [12]. The results clearly demonstrated that commercially available OPC showed highest fluoride reduction as it has all the three forms of calcium sulfate namely $\mathrm{CaSO}_{4} \cdot 2 \mathrm{H}_{2} \mathrm{O}$, $\mathrm{CaSO}_{4} \cdot 0.5 \mathrm{H}_{2} \mathrm{O}$ and soluble $\mathrm{CaSO}_{4} \cdot 0.001 \mathrm{H}_{2} \mathrm{O}$ during the manufacturing process and probably have better dissociation of calcium sulfate ions.

In the present study, the cement was synthesized by adding different forms of gypsum to the clinker, which was ground to pass through $75 \mu \mathrm{m}$ sieve. However, commercially available OPC has a particle size of less than $45 \mu \mathrm{m}$. This could be another reason why the efficiency of synthesized cement containing gypsum in the form of dihydrate and insoluble anhydrate has less fluoride removal efficiency compared to commercially available OPC.

The average values of $\mathrm{pH}$ and conductivity were also measured for the all the controls and experimental samples at different time intervals. The $\mathrm{pH}$ of controls was in the range of 7 to 8 and that of cement slurry was between 11 and 12 . The $\mathrm{pH}$ of the slurry in alkaline range gave the better fluoride removal efficiency. One of the possible reasons is during the hydration of cement, minerals responsible for anion exchange such as ettringite are predominant in this $\mathrm{pH}$ range. The conductivity for controls remained constant at $0.25 \mathrm{mS} / \mathrm{cm}$. However, for the experimental samples it varied in the range of $1 \mathrm{mS} / \mathrm{cm}$ to $6 \mathrm{mS} / \mathrm{cm}$. The highest conductivity value was observed at $30 \mathrm{~min}$ and consecutively showed descending values. When fluoride solution is added to the cement slurry initially dissociation of ions takes place, followed by the formation of minerals. This could be one of the probable reasons for such variations in conductivity [12].

\subsection{Kinetic studies for fluoride removal experiments}

After performing the set of batch experiments for fluoride removal in the presence of different types of modified cement containing different forms of calcium sulfate $5 \%$ $\mathrm{CaSO}_{4} \cdot 2 \mathrm{H}_{2} \mathrm{O}$ and $5 \% \mathrm{CaSO}_{4} \cdot 0.001 \mathrm{H}_{2} \mathrm{O}$ ), clinker and OPC, the kinetic study was carried out for the best results obtained. OPC had the maximum fluoride removal efficiency. In the present study, pseudo-first-order and second-order both the models were studied for the fluoride reduction experiments. However, the kinetic model best fit was obtained for pseudo-first-order kinetics. Similar studies are reported 
Table 1 Rate of reaction constant ' $k$ ' for pseudo-first-order kinetics of different types of cement

\begin{tabular}{lll}
\hline SI. No & Different type of cement & $\begin{array}{l}\text { Reaction constant } \\
\text { ' } k \text { ' value in per hour }\end{array}$ \\
\hline 1 & Clinker & 0.2 \\
2 & OPC & 0.3 \\
3 & $5 \%$ dihydrate & 0.2 \\
4 & $5 \%$ anhydrate & 0.1 \\
\hline
\end{tabular}

Table 2 Fluoride removal kinetics by OPC sample that follows pseudo-first-order kinetics

\begin{tabular}{lll}
\hline Time (mins) & $\begin{array}{l}\text { Concentration of } \\
\text { controls in } \mathrm{mg} / \mathrm{L}\end{array}$ & $\begin{array}{l}\text { Concentration of experi- } \\
\text { mental samples in } \mathrm{mg} / \mathrm{L}\end{array}$ \\
\hline 0 & 30.00 & 30.00 \\
30 & 31.25 & 28.33 \\
60 & 32.50 & 25.83 \\
120 & 28.75 & 15.83 \\
180 & 31.25 & 14.17 \\
240 & 28.75 & 12.50 \\
300 & 30.00 & 11.67 \\
& $R^{2}$ & 0.923 \\
\hline
\end{tabular}

by earlier researchers [15]. Table 1 represents the ' $k$ ' values of pseudo-first-order kinetics for different types of cement. The ' $k$ ' value for clinker and $5 \% \mathrm{CaSO}_{4} \cdot 2 \mathrm{H}_{2} \mathrm{O}$ experiment was $0.2 \mathrm{~h}^{-1}$ and that for $5 \%$ anhydrate was $0.1 \mathrm{~h}^{-1}$. OPC showed the best kinetics for fluoride removal with the highest ' $k^{\prime}$ value of $0.3 \mathrm{~h}^{-1}$ with an $R^{2}$ value of 0.923 . Table 2 shows the pseudo-first-order kinetics fit for the OPC experiment for the removal of fluoride.

\subsection{Fluoride removal efficiency of column packed with OPC granules}

From the results of batch experiments, the column was designed for the removal of fluoride using fresh cement granules of OPC as OPC showed significant reduction for fluoride ions. Cement granules of fresh OPC were prepared with water/cement ratio of 0.3 . The initial concentration of synthetic fluoride solution was $10 \mathrm{mg} / \mathrm{L}$ at a $\mathrm{pH}$ of 8.2 . The synthetic fluoride solution was passed at the flow rate of $40 \mathrm{~mL} / \mathrm{min}$ through the bed of OPC granules (of size varying from 5 to $12 \mathrm{~mm}$ ) having bed height of $35 \mathrm{~cm}$. The fluoride removal efficiency was checked at different time intervals from the 0th day to 10th day of cement hydration. Figure 2 shows the percentage fluoride removal from the column packed with OPC granules at different hydration period starting from 0 to 10 th day. Initially, for a fresh column containing OPC granules without hydration the

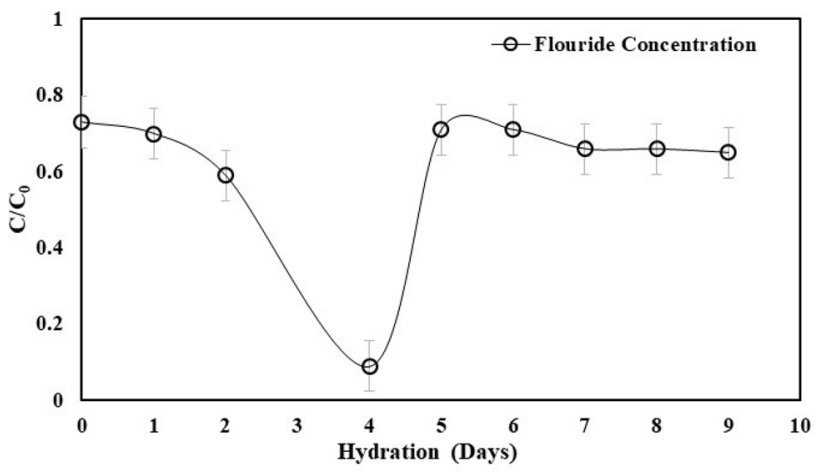

Fig. 2 Fluoride removal by OPC granules at different hydration periods

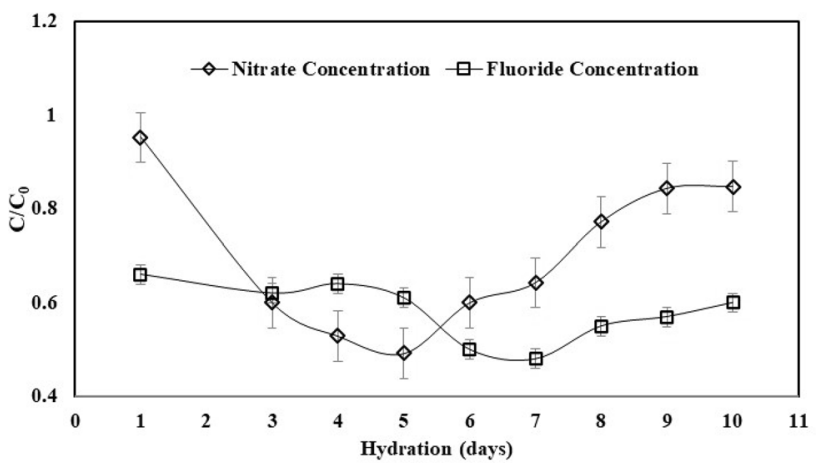

Fig. 3 Removal of nitrate and fluoride ion simultaneously by OPC granules at different hydration periods

fluoride reduction was $27 \%$. It was observed that the fluoride removal efficiency increased to $30 \%$ and $41 \%$ when cement granules were hydrated for the second and third day, respectively. On fourth day of hydration of cement granules, the significant fluoride removal efficiency of $91 \%$ was obtained.

Further, fluoride removal efficiencies of column reduced and were between 29 and $34 \%$ from 5 th day to 10 th day of hydration of OPC granules. Figure 3 shows the percentage fluoride removal of OPC granules at different hydration time starting from 0 to 10th day. The studies have already been carried out for the effect of $\mathrm{pH}$ on formation of cement minerals which are responsible for contaminant removal. It is also documented that ettringite formation enhances by addition of stoichiometric ratios of aluminum sulfate during cement hydration which acts like a sorbent for the removal of toxic anions such as boric acid and fluoride [21]. In the present study, the highest $\mathrm{pH}$ (11.5) was recorded for the column containing fresh granules of cement during fluoride reduction experiments.

Further, the $\mathrm{pH}$ reduced to 9.58 , with an increase in the hydration period. On the fourth day where maximum fluoride removal efficiency was obtained, the $\mathrm{pH}$ was 10.5. The 
studies have reported that the formation and stability of ettringite mineral will be high in the $\mathrm{pH}$ range 10.5 to 11.5 [12]. Beyond 11.5 and below 10.5, the ettringite mineral dissociates and its formation are minimized. Hence in the present study, ettringite minerals got formed more on the fourth day, which had favorable conditions for ettringite generation and fluoride reduction. The reduction in the fluoride removal efficiency could be because of the reduction in the formation of ettringite with a reduction in $\mathrm{pH}$ value.

During the column studies, both calcium and sulfate ions were analyzed, respectively. The fresh column showed $252 \mathrm{mg} / \mathrm{L}$ of calcium and $250 \mathrm{mg} / \mathrm{L}$ of sulfate. Then, calcium and sulfate were consumed to form the cement minerals like $\mathrm{C}-\mathrm{S}-\mathrm{H}, \mathrm{Ca}(\mathrm{OH})_{2}$ and ettringite. The fluoride removal efficiency increased with decreased concentration of calcium and sulfate ions. After obtaining maximum percentage removal of fluoride ion, the effectiveness of the column decreased, and even calcium and sulfate showed lower concentration values of around $44 \mathrm{mg} / \mathrm{L}$ and $3 \mathrm{mg} / \mathrm{L}$. The leaching behavior of calcium and sulfate with respect to hydration days is as shown in Fig. S2.

\subsection{Simultaneous removal of fluoride and nitrate by column containing OPC cement granules}

To check the effect of another anion on fluoride removal, the column experiment was designed to check the simultaneous removal of nitrate and fluoride concentration of $10 \mathrm{mg} / \mathrm{L}$. Previous studies have stated that the anion exchange takes place concerning atomic radii of the molecule in the ettringite mineral. The anion $\mathrm{SO}_{4}{ }^{2-}$ in the ettringite mineral could get replaced sequentially by $\mathrm{CO}_{3}{ }^{-}$, $\mathrm{HCO}_{3}{ }^{-}, \mathrm{Cl}^{-}, \mathrm{NO}_{3}{ }^{-}, \mathrm{NO}_{2}^{-}, \mathrm{PO}_{4}^{-}$and $\mathrm{F}^{-}[22]$. In the present study, nitrate and fluoride ions were reduced to $50.8 \%$ and $39 \%$, respectively, on the fifth day of hydration of cement granules. On the seventh day, fluoride ion was reduced to $52 \%$, and that of nitrate ion decreased to $35.77 \%$. Nitrate reduction was maximum when compared to fluoride reduction on fifth day and on seventh day fluoride reduction was much higher than nitrate reduction.

Figure 3 shows the simultaneous removal of fluoride and nitrate at different hydration periods. From the graph, it can be observed that the nitrate ions are reduced initially on the fifth day of the hydration period. Then, fluoride is reduced on the seventh day of hydration period of cement granules. Probably, the sequence of replaceable anions could be the reason for nitrates to reduce initially then followed by fluoride reduction.

The present study is ongoing and needs further investigation regarding the long-term effect in terms of fluoride removal efficiency of cement column. Cement matrix in a column consisting of cement granules hydrated at different time intervals need to be investigated for longterm effect of fluoride removal capacity.

The cement and fluoride interactions in batch experiments are $\mathrm{pH}$ dependent which affects the fluoride reduction kinetics. The dependency of $\mathrm{pH}$ on reduction and adsorption kinetics is reported by similar researches [23]. The adsorption kinetics for the batch experiments were studied similarly, as reported by earlier researcher [24]. On comparison of pseudo-first-order (Eq. (3)) and pseudo-second-order (Eq. (4)) models, it is inferred that pseudo-second-order data fit well (Fig S3). The values of $q_{e}$ (experimental) and $q_{e}$ (calculated) are in close agreement, as shown in Table S3. The $R^{2}$ values are higher than 0.9492, which indicates the agreement of experimental values to the linear fit. The maximum $R^{2}$ in pseudo-second-order that is 0.9997 was observed concerning cement with $5 \%$ anhydrate. The mechanism in terms of adsorption kinetic models can be further studied in detail and developed for a better understanding of fluoride and cement interactions. This work will be continued in a similar direction, as reported by earlier researchers in the relevant research areas $[24,25]$.

$\log \left(q_{e}-q_{t}\right)=\log q_{e}-\frac{K_{1}}{2.303} t$

$\frac{t}{q_{t}}=\frac{1}{K_{2} q_{e}^{2}}-\frac{1}{q_{e}} t$

\subsection{Mineralogical characterization of the cement samples in column and batch experiment}

To understand the mineralogical changes taking place during the fluoride reduction by cement in the batch experiment and different column conditions, SEM and XRD were carried out. The OPC granule, which gave maximum reduction of $91 \%$ of fluoride reduction in column study on fourth day wherein only fluoride solution was passed, was chosen for SEM analysis. Figure 4 shows the SEM images of the OPC sample taken on the fourth day of cement hydration. Figure 4 represents SEM image at a magnification scale of $20,000 \times$. The presence of rod-like structures of ettringite can be seen in the SEM image (Fig. 4a, b). To validate the presence of ettringite, XRD analysis was carried out for the same OPC granules at the end of fourth day Fig. 5 a.

Figure 5a showed the XRD peaks for fourth day sample with $2 \theta$ value of 22.8 which matched with standard card of Al ettringite, Joint Committee for Powder Diffraction Standards (JCPDS) card no. 720646. Highest peak at 31.9 was found to be Fe-ettringite with card no. 270077. Hence, it clearly shows that ettringite mineral got generated 
Fig. 4 SEM image of OPC sample taken on fourth day of cement hydration during fluoride removal column experiment at varying magnification scale of (a) $20,000 \times(1 \mu \mathrm{m})$ (b) $10,000 \times(1 \mu \mathrm{m})(\mathbf{c}) 5,000$ $\mathrm{X}(5 \mu \mathrm{m})(\mathbf{d}) 3000 \mathrm{X}(5 \mu \mathrm{m})(\mathbf{e})$ $2,000 \times(20 \mu \mathrm{m})(\mathbf{f}) 2,000 \mathrm{X}$ $(10 \mu \mathrm{m})$. Marked part of figure (a) and (b) shows the presence of ettringite rods
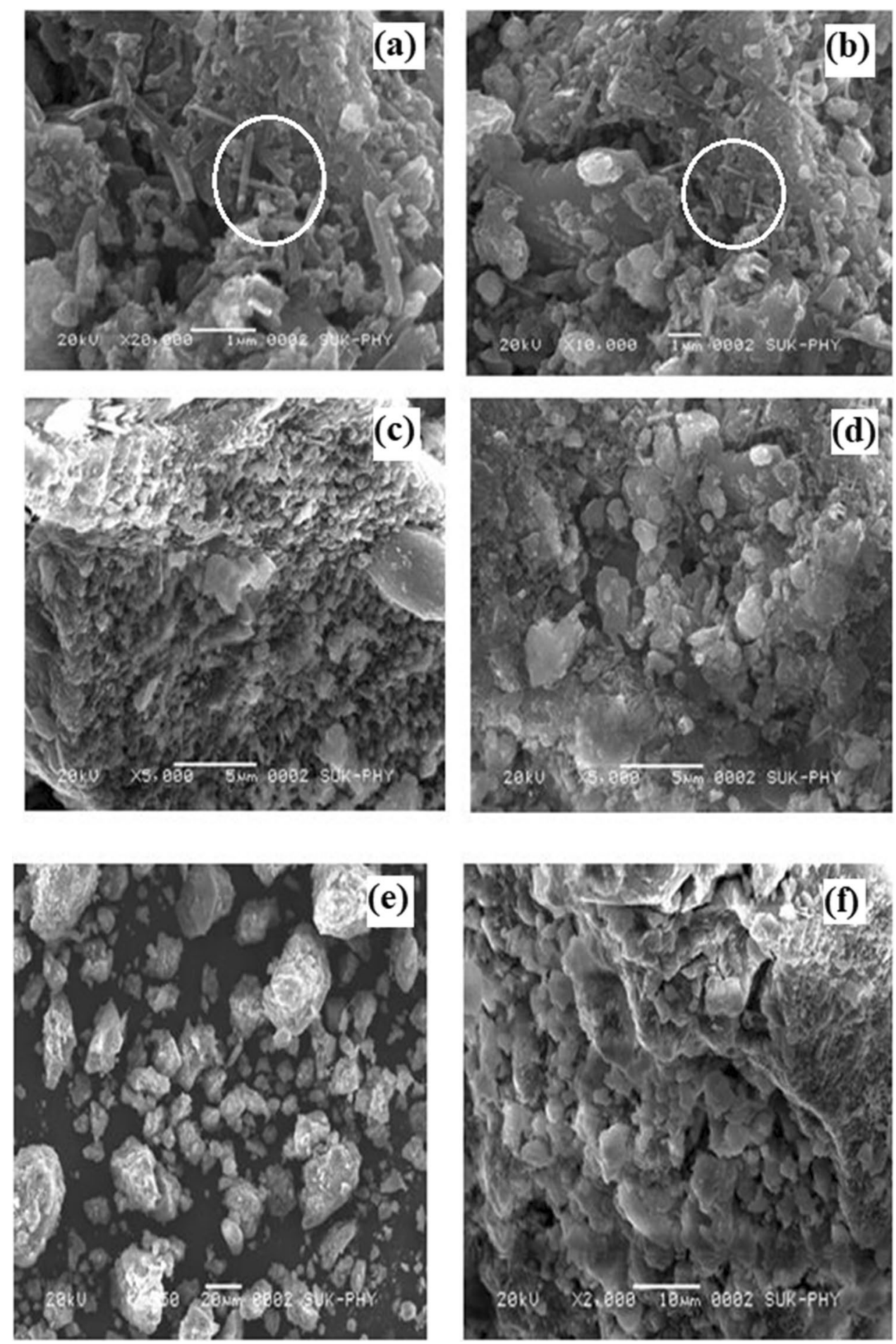

during the reaction, which is in agreement with SEM morphology shown in Fig. 4a, b. From Table S1 and Table S2, it is evident that the percentage of oxides of calcium, aluminum and iron in OPC is more than that available in clinker. Hence, Al-ettringite and Fe-ettringite will get formed more in OPC compared to clinker. From XRD results explained above, the presence of Al-ettringite as well as
Fe-ettringite is seen in the fourth day of hydration of OPC, which showed the highest fluoride removal efficiency.

It is well known that the ettringite minerals are responsible for anion exchange [26], in present experiments column studies with maximum fluoride reduction of $91 \%$ on fourth day could be because of generation of ettringite mineral. However, this peak was absent in 


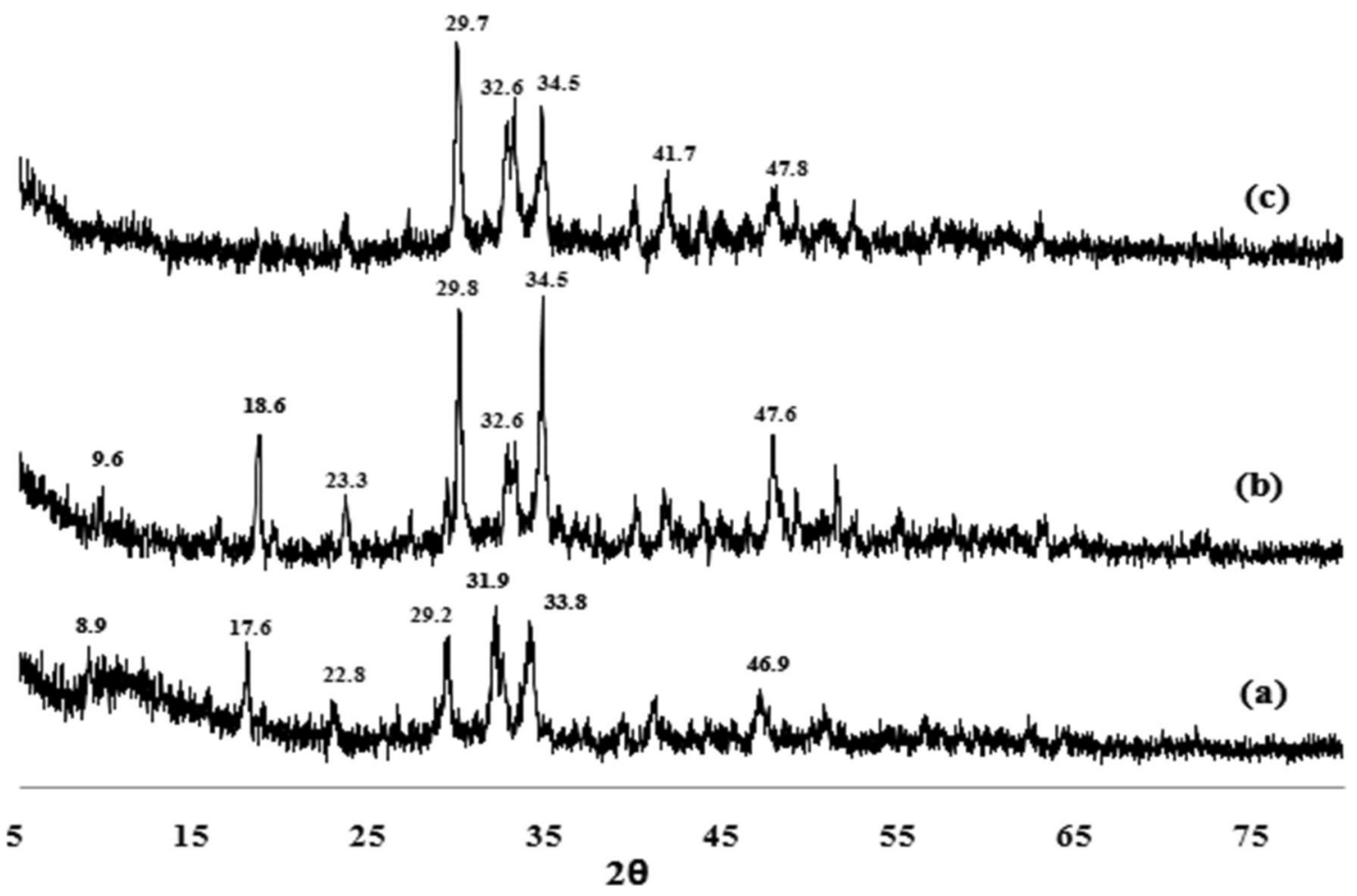

Fig. 5 XRD images taken at the end of fluoride removal experiments of OPC sample on (a) fourth day of column experiment when just fluoride solution passed (b) seventh day of column

experiment when mixture of fluoride and nitrate was passed and (c) 5 th $\mathrm{h}$ of batch experiment with just OPC

the other two samples. The presence of calcium silicate hydrate was also seen at a $2 \theta$ value of 29.2 JCPDS card no. 722396 . The calcium hydroxide presence was also evident at 33.8 JCPDS card no. 841276. The calcium fluoride peak was seen at $2 \theta$ value of 46.9 JCPDS card no. 870971.

To compare minerals generated in the cement granules when the nitrate and fluoride mixture was run in column experiment at the end of the seventh day was chosen for XRD analysis Fig. 5b, additionally the OPC sample of batch experiment at the end of 5 th $\mathrm{h}$ Fig. $5 \mathrm{c}$ was also chosen.

The seventh day sample showed the presence of calcium silicon fluoride peak at 47.6 (JCPDS card no. 010482), and the 5 th $\mathrm{h}$ sample showed calcium fluoride peak at 47.8 (JCPDS card no. 031088). Cement has calcium oxide and fluoride reacted with calcium to give calcium fluoride minerals. Similar studies are reported by earlier researchers where the potential of minerals such as $\mathrm{CaO}, \mathrm{CaCl}_{2}$ and $\mathrm{MgO}$ to reduce fluoride is reported $[27,28]$. The samples on seventh day and $5 \mathrm{~h}$ showed the presence of calcium silicate hydrate and form of calcium hydroxide with similar $2 \theta$ values of 32.6 and 34.5 , respectively. The peaks matched with JCPDS card no. 721907 and 491,195. The presence of calcium sulfate hydrate peak was observed in both samples at value 29.7 (JCPDS no. 140453).

\section{Conclusions}

OPC showed pseudo-first-order kinetics in removing fluoride in batch experiments with the highest kinetics as compared to clinker, cement containing calcium sulfate dihydrate and cement containing calcium sulfate anhydrate (insoluble). Fluoride removal was then analyzed for column experiments with optimized OPC sample by prepared cement granules. The cement granules could treat fluoride synthetic solution to the acceptable level. The efficiency of fluoride removal was observed maximum at high $\mathrm{pH}(10-12)$, and gradually the efficiency reduced at lower $\mathrm{pH}(<10)$. Further nitrate was also simultaneously removed in the earlier stages in the column and then followed by fluoride removal by the minerals present in cement granules. The SEM and XRD analysis showed the evidence of ettringite minerals in the column experiments where fluoride was reduced by $91 \%$. However, these minerals were absent in the other two samples. The presence of calcium fluoride and calcium silicon fluoride was seen in cement samples. It is clearly evident that fluoride reduction in cement hydration reaction takes place because of multiple mechanisms. 


\section{Compliance with ethical standards}

Conflict of interest The authors declare that they have no conflict of interest.

\section{References}

1. Farfan MDJ, Guerrero JCH, Lopez LAJ, Aleman LFJ, Hernandez JF (2011) Fluoride consumption and its impact on oral health. Int J Environ Res Public Health 28:148-160. https://doi.org/10.3390/ ijerph8010148

2. Ozsvath DL (2009) Fluoride and environmental health: a review. Rev Environ Sci Biotechnol 8:59-79. https://doi.org/10.1007/ s11157-008-9136-9

3. Bureau of Indian Standards (BIS) IS 10500:2012 Indian standard drinking water-specification, second revision, New Delhi

4. World Health Organization (WHO) (2007) Nitrate and fluoride in drinking-water background document for development of WHO guidelines for drinking-water quality. WHO/SDE/WSH/07.01/16

5. Arora M, Maheshwari RC (2006) Fluoride in drinking water and its removal. J Hazard Mater 137:456-463. https://doi. org/10.1016/j.jhazmat.2006.02.024

6. Singh J, Singh P, Singh A (2016) Fluoride ions versus removal technologies: a study. Arab J Chem. https://doi.org/10.1016/j. arabjc.2014.06.005

7. Sarkar M, Banerjee A, Pramanick PP, Sarkar AR (2007) Design and operation of fixed bed laterite column for the removal of fluoride from water. Chem Eng J 131:329-335. https://doi. org/10.1016/j.cej.2006.12.016

8. Hamdi N, Srasra E (2007) Removal of fluoride from acidic wastewater by clay mineral: effect of solid-liquid ratios. Desalination 206:238-244. https://doi.org/10.1016/j.desal.2006.04.054

9. Batchelor B (2006) Overview of waste stabilization with cement. Waste Manag 26:689-698. https://doi.org/10.1016/j.wasma n.2006.01.020

10. Baur I, Keller P, Mavrocordatos D, Wehrli B, Johnson C (2004) Dissolution-precipitation behaviour of ettringite, monosulfate, and calcium silicate hydrate. Cem Conc Res 34:341-348

11. Yousuf M, Mollah A, Vempati R, Lin TC, Cocke DL (1995) The interfacial chemistry of solidification/ stabilization of metals in cement and pozzolanic material systems. Waste Manag 15:137148. https://doi.org/10.1016/0956-053X(95)00013-P

12. Taylor HFW (1997) Cement chemistry, 2nd edn. Thomas Telford Services Ltd., London

13. Keller IRB (2002) The immobilisation of heavy metals and metalloids in cement stabilised wastes: a study focussing on the selenium oxyanions $\mathrm{SeO}_{3}{ }^{2-}$ and $\mathrm{SeO}_{4}{ }^{2-}$. Dissertation, University of zurich, Switzerland

14. Ghorpade PA, Ha MG, Park JY (2015) Effect of different types of calcium sulfate on the reactivity of cement/Fe(II) system in dechlorination of trichloroethylene. Desalin Water Treat. https ://doi.org/10.1080/19443994.2014.950342

15. Park JY, Byun HJ, Choi WH, Kang WH (2008) Cement paste column for simultaneous removal of fluoride, phosphate, and nitrate in acidic wastewater. Chemosphere 70:1429-1437. https ://doi.org/10.1016/j.chemosphere.2007.09.012
16. Choi WH, Ghorpade PA, Kim KB, Shin JW, Park JY (2012) Properties of synthetic monosulfate as a novel material for arsenic removal. J Hazard Mater 228:402-409. https://doi.org/10.1016/j. jhazmat.2012.05.082

17. Kang WH, Kim El, Park JY (2007) Fluoride removal capacity of cement paste. Desalin Water Treat 202:38-44. https://doi. org/10.1016/j.desal.2005.12.036

18. Zuari Cement, Heidelberg Cement Group, Test certificate

19. Kanoria Group, Bagalkot cement and industries test certificate

20. American Public Health Association; American Water Works Association; Water Environment Federation (2005) Standard methods for the examination of water and wastewater, 21st edn. American Public Health Association, Washington. https:// doi.org/10.1016/j.cemconres.2003.08.016

21. Tsunashima Y, lizuka A, Akimoto J, Hongo T, Yamasaki A (2012) Preparation of sorbents containing ettringite phase from concrete sludge and their performance in removing borate and fluoride ions from waste water. Chem Eng J 200-202:338-343. https://doi.org/10.1016/j.cej.2012.06.064

22. Brahman KD, Kazi TG, Afridi HI, Naseem S, ArainS S, Ullah N (2013) Evaluation of high levels of fluoride, arsenic species and other physicochemical parameters in underground water of two subdistricts of Tharparkar, Pakistan: a multivariate study. Water Res 47:1005-1020. https://doi.org/10.1016/j.watres.2012.10.042

23. Vecino X, Rey RD, Villagrasa S, Cruz JM, Moldes AB (2015) Kinetic and morphology study of alginate-vineyard pruning waste biocomposite versus non modified vineyard pruning waste for dye removal. J Environ Sci 38:158-167. https://doi.org/10.1016/j. jes.2015.05.032

24. Perez-Ameneiro M, Vecino X, Barbosa-Pereira L, Cruz JM, Moldes $A B$ (2014) Removal of pigments from aqueous solution by a calciumalginate-grape marc biopolymer: a kinetic study. Carbohydr Polym 101:954-960. https://doi.org/10.1016/j.carbp ol.2013.09.091

25. Perez-Ameneiro M, Bustos G, Vecino X, Barbosa-Pereira L, Cruz JM, Moldes AB (2015) Heterogenous Lignocellulosic Composites As Bio-Based Adsorbents For Wastewater Dye Removal: A Kinetic Comparison. Water Air Soil Pollut 226:133. https://doi. org/10.1007/s11270-015-2393-7

26. Tian X, Zhou Z, Xin Y, Jiang LM, Zhao X, Ying A (2019) A novel sulfate removal process by ettringite precipitation with aluminium recovery: Kinetics and a pilot-scale study. J Hazard Mater. https ://doi.org/10.1016/j.jhazmat.2018.11.032

27. Karunanithi M, Agarwal R, Qanungo K (2019) A review of fluoride removal from groundwater. Period Polytech Chem. https://doi. org/10.3311/PPch.12076

28. Gogoi S, Dutta RK (2015) Mechanism of fluoride removal by phosphoric acid-enhanced limestone: equilibrium and kinetics of fluoride sorption. Desalin Water Treat. https://doi. org/10.1080/19443994.2015.1010592

Publisher's Note Springer Nature remains neutral with regard to jurisdictional claims in published maps and institutional affiliations. 